perifèria

Número 4, juliol 2006

www.periferia.name

\title{
Dones que anaven pel món. Estudi etnogràfic de les trementinaires de la Vall de la Vansa i Tuixent
}

\author{
Joan Frigolé Reixach - Universitat de Barcelona \\ Temes d'Etnologia de Catalunya, 12
}

Barcelona: Departament de Cultura, Generalitat de Catalunya, 2005

235 pàgines

\section{Resum}

Estudi etnogràfic de dones venedores ambulants d'herbes remeieres i trementina, entre d'altres productes, per a la gent i el bestiar. L'estudi situa les trajectòries de les trementinaires en el context d'una societat i d'una economia en què la pluriactivitat, sovint associada a la mobilitat, era una estratègia bàsica de subsistència. L'estudi retrata l'evolució i declivi de l'activitiat de les trementinaires al llarg del segle XX i la seva reaparició posterior com a figures de museu, és a dir, la seva conversió en un bé patrimonial i en un símbol d'identitat local. El Ilibre, resultat d'una recerca feta per a I'Inventari del Patrimoni Etnològic de Catalunya (IPEC), consta d'una presentació, tres capítols i annexos, i conté una quarantena de fotos, la majoria d'època.

\section{Resumen}

Estudio etnográfico de mujeres vendedoras ambulantes de hierbas remediadoras y trementina, entre otros productos, para las personas y el ganado. El estudio sitúa las trayectorias de las trementinaires en el contexto de una sociedad y de una economía en la que la pluriactividad, a menudo asociada a la movilidad, era una estrategia básica de subsistencia. El estudio retrata la evolución y el declive de la actividad de las trementinaires a lo largo del siglo XX y su reaparición posterior como figuras de museo, es decir, su conversión en un bien patrimonial y en un símbolo de identidad local. El libro, resultado de una investigación realizada para el Inventari del Patrimoni Etnològic de Catalunya (IPEC), consta de una presentación, tres capítulos y anexos, así como de una cuarentena de fotos, la mayoría de la época. 


\section{perifèria}

\section{Número 4, juliol 2006}

www.periferia.name

L'estudi situa les trajectòries de les trementinaires en el context d'una societat i d'una economia agràries en què la pluriactivitat, sovint associada a la mobilitat, era una estratègia bàsica de subsistència. Les trementinaires eren venedores ambulants, principalment d'herbes remeieres i trementina per a la cura de gent i bestiar. L'expressió local "dones que anaven pel món" destaca la interconnexió, però també la jerarquia, entre dos territoris: el país, la vall de la Vansa i Tuixén (L'Alt Urgell), i la resta de Catalunya, el món que recorrien. El país necessitava el món per sobreviure i feia un gran esforç --fins a finals de la dècada de 1940 no es varen obrir pistes de terra--, per no desconnectar-se'n. La desconnexió hauria comportat un agreujament de les condicions de vida i més despoblament.

La unitat bàsica és la casa com a conjunt d'edificis, patrimoni i persones, amb un nom i una identitat col-lectiva. El règim de les cases era jeràrquic. Les filles i les joves ocupaven un dels rangs inferiors dins d'aquest ordre jeràrquic. L'alternança de sedentarisme i mobilitat dels integrants d'una casa era resultat d'estratègies familiars de regulació, que afectaven també als seus matrimonis. Les trementinaires eren dones -només uns pocs homes adults acompanyaren les seves esposes, i només conec un cas d'un home que hi anés sol--, membres de cases baixes per naixement o casament. Moltes trementinaires havien començat anant pel món com a acompanyantes de les seves mares o d'altres dones que les llogaven. Les més petites podien tenir vuit o nou anys. Als tretze o catorze anys, si tenien germanes petites que les poguessin substituir, les enviaven a servir, però d'altres seguien anant pel món fins a l'edat adulta. Els nens també acompanyaven les seves mares, sobretot quan no tenien germanes. La majoria de dones al casarse entraven a formar part de la casa del marit com a joves. Si la casa era baixa o tenia deutes que posaven en perill el patrimoni, era molt probable que la jove anés pel món, encara que no hi hagués anat abans. Aquestes dones, sense fills o amb fills encara molt petits, s'associaven sovint amb dones adultes, familiars seves o no, amb més experiència o més habilitat comercial. Les trementinaires havien de compatibilitzar marxar lluny de casa i caminar carregades amb les limitacions que els imposava la reproducció, és a dir, la gestació, el part i la criança dels fills, encara que el sistema reproductiu era concebut i practicat d'una manera més flexible que, per exemple, en èpoques posteriors. La generació més vella -- si encara era viva--, el marit, les filles grans havien d'assumir una part de les tasques 


\section{perifèria}

\section{Número 4, juliol 2006}

www.periferia.name

de la criança. A vegades, per poder continuar la seva activitat comercial, la dona deixava el fill a una dida, una dona que estava criant el seu. Les dones que anaven pel món contribuïen a l'economia domèstica de dues maneres complementàries: amb l'estalvi en no menjar a casa $\mathrm{i}$ aportant-hi els diners guanyats amb la comercialització de les herbes, bolets i trementina. La seva posició social la reforçava tant l'èxit reproductor com comercial.

Les trementinaires comercialitzaven recursos del país i també foranis, però els productes locals eren una part molt important de la seva venda. El medi local proporcionava una gran diversitat d'herbes amb aplicacions remeieres. El seu aprofitament suposava en primer lloc coneixements referits a la identificació, localització, època i forma de recol-lecció de les plantes o d'algunes de les seves parts i, en segon Iloc, referits a l'assecat, tall, i collocació de les herbes en envasos. Les herbes les posaven en coixineres, que reunien en una gran bossa que portaven penjada de l'esquena a la manera d'una motxilla, i les resines les envasaven en llaunes que també portaven penjades. Abans de l'obertura de les pistes, es comercialitzaven bolets frescos, però en quantitats relativament petites degut a les dificultats del transport cap a La Seu d'Urgell o cap a pobles del Solsonès. Les trementinaires solien comercialitzar bolets secs que portaven al sortir de la vall o que havien enviat per endavant a certes destinacions pels sistemes de transport disponibles. Aquestes bolets secs, que venien per moixernons, eren el resultat d'una sèrie d'operacions que acabaven convertint un bolet diferent, molt abundant però poc apreciat, en un producte valuós. Les operacions que aportaven valor afegit a aquest recurs eren les de pelar, tallar en trossets, assecar, i finalment, enfilar formant collarets. Solien fer-se els vespres i hi solia participar tot el grup domèstic El resultat final: poc pes, poc volum, característiques bàsiques per la mobilitat, i un valor elevat.

El conjunt de plantes bàsiques que venien estava constituït per hisop (Hyssopus officinalis), orella d'ós (Ramonda myconi), corona de rei (Saxifraga longifolia), corner (Amelnachier ovalis), te de roca (Jasonia glutinosa) i salsufragi (Silene saxifraga). Però el ventall era més gran, ja que podia incloure algunes de les següents: til·la, sajolida, orenga, sàlvia, comí petit (Carum carvi), escarcí (Viscum album), milfulles (Achiella millefolium), herba blanca (Polygola calcarea), camamilla, peu de Crist (Potentilla reptans), donzell (Artemisia absinthium), 


\section{perifèria}

Número 4, juliol 2006

www.periferia.name

genciana, flor de saüc, escabiosa (Knautia arvensis), serpildó (Thymus serpyllum), serverola (Agrimonia eupatoria), etc.

La trementina, el producte pel que eren conegudes fora del país, no era l'únic producte resinós que comercialitzaven, però sí el més destacat, ja que era molt demandat degut a les seves múltiples aplicacions curatives, habitualment en forma de pegats. Almenys al segle vint, les trementinaires compraven la trementina a drogueries o l'elaboraven amb els components bàsics, pega grega i aiguarràs, comprats a drogueries, als què hi podien afegir components casolans per tal d'obtenir productes derivats, com l'ungüent de trementina. Tant la compra com l'elaboració de la trementina o derivats podien fer-les al llarg dels seus itineraris per respondre de manera flexible i ràpida a la demanda.

Les trementinaires elaboraven també diversos olis, com l'oli per trencar el tifus, o productes com el "tabaco negre" usat contra la diftèria. Les trementinaires disseminaven també el coneixement de receptes i remeis i, en alguns casos, els aplicaven. Aconseguir la confiança de la clientela era bàsic per la continuïtat de I'activitat, però a vegades es trencava degut a que els remeis resultaven inadequats o ineficients. Llavors podien acusar-les d'engany o mala fe.

El territori recorregut per les trementinaires era sobretot rural, amb àrees de poblament dispers i d'altres de concentrat, però també periurbà i, en menor mesura urbà, ciutats grans a les què adaptaven les seves formes de venda. El territori per què es desplaçaven incloïa la major part de la franja litoral i prelitoral, lloc d'hivernada dels ramats transhumants. Les trementinaires segons les temporades recorrien diferents parts de Catalunya. Solien dirigir-se durant la tardor cap al pla d'Urgell i comarques properes. Passaven el Nadal a casa. Al mes de gener es dirigien cap les parts central i nordoriental de Catalunya. L'expressió "Rams amunt, Pascua a casa" indica el final de la segona sortida.

Les trementinaires procuraven establir relacions de reciprocitat amb la gent per tal de procurar-se allotjament i alimentació sense gastar diners. Ajudaven en les cases durant el temps que les acollien o al marxar els hi donaven petites quantitats dels seus productes. 


\section{perifèria}

Número 4, juliol 2006

www.periferia.name

Un canvi decisiu es va produir quan la generació de dones nascudes cap a finals de la dècada de 1910 només va acompanyar a la generació de les seves mares mentre eren petites, però no va prendre'n el relleu quan varen ser adultes.

La recuperació de la figura de les trementinaires cap a final de segle constitueix la creació d'una tradició selectiva. Les trementinaires es convertiren en un bé patrimonial i en símbol d'identitat local amb la creació del Museu de les Trementinaires a Tuixent. La conversió d'un element poc valorat en el passat en un element valuós en el present no és deguda a una motivació nostàlgica o tradicionalista, sinó que reflecteix una resposta local a forces globals que orienten l'economia local cap al turisme i els serveis. Les trementinaires assumeixen de nou simbòlicament la funció de portar recursos del món cap al país, no anant pel món, sinó fent que el món vagi cap al seu museu.

La base empírica de l'estudi prové de la informació proporcionada per cinquantanou persones de diversos pobles, homes i dones, amb experiència directa d'anar pel món o sense, i del treball de camp etnogràfic fet a la vall entre el 2002 i el 2004.

El llibre, resultat d'una recerca feta per a l'Inventari del Patrimoni Etnològic de Catalunya (IPEC), consta d'una presentació, tres capítols i annexos, i conté una quarantena de fotos, la majoria d'època. 